Methods: Six sedentary men, treated with diet and/or a hypoglycemic agent performed four exercise sessions at $60 \%$ of their $\mathrm{VO}_{2}$ peak, in the fasted state or 2 hours after a standardized breakfast, with and without BB (Atenolol $100 \mathrm{mg}$ id for five consecutive days). Blood samples were assayed during the resting period, at 15-minutes intervals during the exercise session and the recovery period.

Results: A reduction of blood glucose levels was observed following the exercise session performed in the postabsorptive state $(41 \%$ and $37 \%$ reduction with and without $\mathrm{BB}$ treatment respectively; $P<0.01)$. One hour of exercise performed in the fasted state had minimal impact on glucose and insulin levels, with or without BB. BB treatment was not associated with increased baseline blood glucose or insulin levels in the fasted or the postabsorptive situation.

Conclusion: These results suggest that the nutritional status has a more important impact on plasma glucose and insulin modulation than short-term use of BB per se.

\section{Aerobic Capacity of Elderly People after a Short 6- Week Intermittent Exercise Programme}

Lonsdorfer-Wolf Evelyne, Stéphane Doutreleau, Ruddy Richard, Bernard Geny, Dept of Physiology and UPRES 3072, University Hospital, Strasbourg, France

Jean Lonsdorfer, Dept of Gerontology, University

Hospital, Strasbourg, France

Background: One of the most debilitating effects of advancing age is the progressive decline in aerobic exercise capacity. To prevent this decrease, exercise prescription has been proved to be effective in compensating for the age-associated decline in maximal oxygen capacity.

Methods: 27 healthy sedentary elderly men (10) and women (17) aged $67 \pm 7 \mathrm{yr}$, were involved in a tailored 6-week intermittent exercise programme, with $30 \mathrm{~min}$ cycling per session, 3 times a week. One session alternated $4 \mathrm{~min}$ at a workload corresponding to the ventilatory threshold (called "bases") and $1 \mathrm{~min}$ to a charge corresponding to $90 \%$ of the maximum toler- ated power of the subjects (called "peaks"). This was repeated 6 times during one session. To determine these charges, all subjects underwent a 1-minute-step maximal incremental exercise test to find out their maximal tolerated power, peak oxygen consumption ( $\mathrm{VO}_{2}$ peak), maximal heart rate, and maximal lactate. A second maximal incremental exercise test was performed after the programme, to compare the different parameters.

Results: For the whole group, maximal tolerated power increased from $113 \pm 8$ watts to $13 \pm 9$ watts $(P<0.001), \mathrm{VO}_{2}$ peak increased from $19.8 \pm 0.9 \mathrm{ml} \cdot \mathrm{kg}^{-}$ ${ }^{1} \cdot \mathrm{min}^{-1}$ to $22.2 \pm 0.9 \mathrm{ml} \cdot \mathrm{kg}^{-1} \cdot \mathrm{min}^{-1}(P=0.002)$, maximal heart rate $\left(143 \pm 4\right.$ vs $144 \pm 4$ beats $\left.\cdot \mathrm{min}^{-1}\right)$ and maximal lactate $\left(5.4 \pm 0.3\right.$ vs $\left.5.7 \pm 0.3 \mathrm{mmol} \cdot \mathrm{L}^{-1}\right)$ did not change.

$\mathrm{VO}_{2}$ at ventilatory threshold increased from $950 \pm 57$ $\mathrm{ml} \cdot \mathrm{min}^{-1}$ to $1095 \pm 69 \mathrm{ml} \cdot \mathrm{min}^{-1}(P=0.007)$, and the corresponding power increased from $65 \pm 5$ watts to $82 \pm 6$ watts $(P<0.001)$.

Conclusions: Even after a short time training programme (6 weeks), we observed a significant improvement in aerobic capacity, and especially in submaximal workloads, which represented, for these subjects, their daily-life capacity.

\section{Susceptibility to Muscle Fatigue and Lung Me- chanics in Chronic Obstructive Pulmonary Disease}

Pepin Véronique, Didier Saey, Claude H. Côté, Pierre LeBlanc, François Maltais, Hôpital Laval, Institut universitaire de cardiologie et de pneumologie de l’Université Laval, Québec, Qc, Canada.

Background: Contractile fatigue of the quadriceps occurs in a significant proportion of patients with COPD after constant-load cycling exercise. Dynamic hyperinflation, by altering cardiac output during exercise, could contribute to fatigue susceptibility in this population. The purpose of this study was to compare operational lung volumes during constant workrate exercise between COPD patients who do and those who do not develop contractile fatigue of the quadriceps (fatiguers vs non-fatiguers).

Methods: Sixty-two patients with COPD $\left(\mathrm{FEV}_{1}\right.$ : $46 \pm 16 \%$ ) completed a constant-load cycling test at 